RESEARCH REPORT

\title{
Assessment of the magnitude of geographical variations and socioeconomic contextual effects on ischaemic heart disease mortality: a multilevel survival analysis of a large Swedish cohort
}

\author{
Basile Chaix, Maria Rosvall, Juan Merlo
}

J Epidemiol Community Health 2007;61:349-355. doi: 10.1136/jech.2006.047597

See end of article for authors' affiliations

Correspondence to:

Dr B Chaix, UMR-S 707

Inserm-Université Pierre et Marie Curie-Parise Faculté de Médecine Saint-Antoine, 27 rue Chaligny, 75012 Paris6, France; chaix@u707.jussieu.fr

Accepted 29 May 2006

\begin{abstract}
Background: In a public health perspective, it is of interest to assess the magnitude of geographical variations in ischaemic heart disease (IHD) mortality and quantify the strength of contextual effects on IHD.

Objective: To investigate whether area effects vary according to the individual and contextual characteristics of the population, socioeconomic contextual influences were assessed in different age groups and within territories of differing population densities.

Design: Multilevel survival analysis of a 28 -year longitudinal database.

Participants: 341048 residents of the Scania region in Sweden, reaching age 50-79 years in 1996, followed up over 7 years.

Results: After adjustment for several individual socioeconomic indicators over the adult age, Cox multilevel models indicated geographical variations in IHD mortality and socioeconomic contextual effects on the mortality risk. However, the magnitude of geographical variations and strength of contextual effects were modified by the age of individuals and the population density of their residential area: socioeconomic contextual effects were much stronger among non-elderly than among elderly adults, and much larger within urban territories than within rural ones. As a consequence, among non-elderly residents of urban territories, the socioeconomic contextual effect was almost as large as the effect of individual 20-year cumulated income. Conclusions: Non-elderly residents of deprived urban neighbourhoods constitute a major target for both contextual epidemiology of coronary disease and public health interventions aimed at reducing the detrimental effects of the social environment on IHD.
\end{abstract}

individual and contextual characteristics of the populations may also create fluctuations in the magnitude of geographical variations and contextual effects.

In this study, to contribute to the assessment of the strength of contextual effects on IHD, we first examined the extent to which contextual influences varied by age of the population considered. The steep increase in IHD risk over the life course may create differences in the magnitude of contextual effects between adults and elderly people. On the basis of previous literature, ${ }^{11} 26^{34}$ we assumed that detrimental social conditions have a stronger role in premature mortality than in older-age mortality, and that the healthy survivor effect may flatten the socioeconomic gradient at older ages. We, therefore, expected a weaker socioeconomic contextual effect among elderly than among non-elderly adults.

On the other hand, our investigation of socioeconomic contextual effects on IHD mortality was conducted within the whole region of Scania, Sweden-that is, within territories of varying population densities. Most previous contextual studies were conducted within urban territories ${ }^{4}$; it is therefore of interest to compare the magnitude of socioeconomic contextual effects between territories of contrasted population densities. We hypothesised a stronger effect of the socioeconomic environment in densely than in sparsely populated territories, as the causal agents of the socioeconomic contextual effect

Abbreviations: ICD, International Classification of Diseases; IDR, interdecile range; IHD, ischaemic heart disease; IHR, interquartile hazard ratio; $I Q R$, interquartile range; $M H R$, median hazard ratio that is, incidence, 1217212427 prevalence $^{8916183132}$ or mortality. ${ }^{11} 19202223263033$ Moreover, differences between studies in the 
Table 1 Variations in ischaemic heart disease mortality between local areas in the region of Scania among individuals aged 50-64 years at baseline, as assessed with empty Cox multilevel models, 1996-2002

\begin{tabular}{lllll} 
& Area variance & IHR & MHR & Intra-area correlation \\
\hline Whole region of Scania & $0.22(p<0.001)$ & 2.91 & 1.57 & 0.12 \\
First tertile of pop density & $0.09(p=0.22)$ & 1.98 & 1.33 & 0.05 \\
Second tertile of pop density & $0.14(p=0.10)$ & 2.34 & 1.42 & 0.08 \\
Third tertile of pop density & $0.21(p<0.001)$ & 2.87 & 1.55 & 0.11
\end{tabular}

IHR, interquartile hazard ratio; MHR, median hazard ratio; pop, population

(whatever they might be) may be more concentrated around individuals in high-density areas.

To deal with these issues, we considered a large cohort comprising all individuals living in the Scania region reaching age 50-79 years in 1996. All those individuals were followed up over 7 years, to assess occurrence of IHD mortality. There were two successive steps in our strategy to assess the importance the residential context may have for IHD mortality. Firstly, we used multilevel survival models to quantify the magnitude of variations between areas in mortality risk, using different approaches to express geographical variability on the commonly used hazard ratio (HR) scale. ${ }^{35}{ }^{36}$ Secondly, we estimated the effect of the socioeconomic environment on IHD mortality adjusted for individual factors, and compared its magnitude with the effect of individual income. Overall, our study expands on previous literature by using complementary approaches to quantify the importance the residential context may have for IHD mortality, and assessing whether contextual influences differ in magnitude by age of individuals and population density of the area of residence.

\section{METHODS}

\section{Data sources}

With the help of Statistics Sweden and the Swedish Centre for Epidemiology, a longitudinal database including all inhabitants of Scania, Sweden (about one million) was assembled (LOMAS). We used the personal identification number assigned to each person in Sweden to link the following data sources:

- the exact spatial coordinates of the households on 1 January 1996 for all Scanian residents reaching age 50-79 years in 1996;

- yearly information on individual income from 1975 to 1995 from the Swedish Population Register;

- education and occupation data from the 1970 population census; and

- date and causes of death from the National Mortality Register.

We constituted a cohort with 1 January 1996 as baseline, comprising all Scanian inhabitants reaching age 50-79 years in 1996. The database was split into two parts to investigate separately individuals aged 50-64 years and 65-79 years at baseline. The cohort comprised 192840 individuals aged 50-64, and 148208 individuals aged 65-79 years at baseline.

\section{Measures}

We defined IHD deaths using the International Classification of Diseases (ICD) as ICD-9 codes $410-414$ or ICD- 10 codes I20-I25 for the underlying or contributing causes of death.

Besides age and gender, we considered marital status, as an indicator of familial support and help, and information on individual socioeconomic position over the adult life-that is, education, occupation 25 years before baseline and individual cumulated income over the past 20 years. Age was coded in 5year categories. Marital status was dichotomised into married/ cohabiting and living alone (ie single, divorced or widowed). Education (from the 1970 census) was divided into three classes $(\leqslant 7,8-9$ and $>9$ years). Occupation 25 years before baseline was defined from 1970 census data. We distinguished between non-manual, manual, self-employed, farmers and others.

Rather than household income, only individual income was available. To adjust for the cumulated effects of wealth/poverty over time, ${ }^{9}$ we considered annual income in 1975, 1980, 1985, 1990 and 1995, converted each income variable into a rank between 1 and 100 to obtain values comparable across years, and computed the average of the five variables for each individual. The cumulated income variable was divided into four categories using the quartiles of the distribution.

To investigate contextual effects on a more local scale than heretofore, we used the smallest existing geographical units. However, some of those units contain no or very few inhabitants. To define the socioeconomic contextual factor in areas containing a minimum number of inhabitants, we used an algorithm to group non-inhabited parcels with adjacent ones. This algorithm aggregates each parcel with $<100$ inhabitants aged 50-89 years with the one of the adjacent parcels that

- belongs to the same neighbourhood and

- shares the longest common boundary.

In 1996, the median number of inhabitants in the resulting 1672 local areas was 559 (interquartile range (IQR) 391-801; interdecile range (IDR) 313-1116), and the median number of individuals aged 50-79 years was 169 (IQR 120-246; IDR 98$348)$. The median area size was $0.4 \mathrm{~km}^{2}$. Its IQR $(0.1-2.2)$ and IDR (0.1-24.7) reflect the larger size of areas in rural settings.

Two contextual factors were considered: population density and socioeconomic environment. Area population density was computed as the number of 50-79-year-old residents $/ \mathrm{km}^{2}$. To define population density strata, we divided the variable into three categories comprising a similar number of individuals. Socioeconomic environment was defined as area mean income of the 50-79-year-old residents at 1 year before baseline. It was divided into four categories that included a similar number of individuals.

\section{Statistical analysis}

To quantify area-level variations in IHD mortality, we estimated multilevel Cox proportional hazards regression models, ${ }^{37}$ with individuals nested within local areas. Individuals were followed up until death, or until the end of a 7-year period (31 December 2002). Such a model extends the usual Cox model by incorporating a random intercept-that is, by allowing the intercept value to vary from one area to another. Including an area-level random intercept in the linear predictor, this model is 
Table 2 Variations in ischaemic heart disease mortality between local areas in the region of Scania among individuals aged 65-79 years at baseline, as assessed with empty Cox multilevel models, 1996-2002

\begin{tabular}{lllll} 
& Area variance & IHR & MHR & Intra-area correlation \\
\hline Whole region of Scania & $0.05(p<0.001)$ & 1.71 & 1.25 & 0.03 \\
First tertile of pop density & $0.03(p=0.16)$ & 1.45 & 1.17 & 0.02 \\
Second tertile of pop density & $0.08(p<0.001)$ & 1.91 & 1.31 & 0.05 \\
Third tertile of pop density & $0.05(p<0.001)$ & 1.68 & 1.24 & 0.03 \\
\hline
\end{tabular}

IHR, interquartile hazard ratio; MHR, median hazard ratio; pop, population

able to account for the fact that individuals residing in the same local area have more similar survival outcomes than individuals from different areas. Assuming that the area-level random intercept is normally distributed, the model estimates its variance, which allows one to both control for within-area correlation and assess the magnitude of between-area variations. As we found no evidence of variations between areas for the effects of individual variables, only the random intercept was included in the model. Using the R software, ${ }^{38}$ the randomeffect Cox regression models were estimated with a penalised likelihood method. ${ }^{39}$

To facilitate assessment of area differences, ${ }^{56}$ we first expressed variations on the hazard ratio (HR) scale with an interquartile hazard ratio $(\mathrm{IHR})^{7}$ and a median hazard ratio (MHR). ${ }^{35}{ }^{40}$ Simulating area-level residuals from their distribution, the IHR expresses the difference in IHD mortality between the $25 \%$ of all individuals in areas with the lowest risk and the $25 \%$ of all individuals in areas with the highest risk. ${ }^{7}$ The MHR is the median value of the HR between the individual in the area with the lowest risk and the individual in the area with the highest risk when randomly picking out two individuals in different areas. ${ }^{35}{ }^{40}$ Secondly, following previous literature, ${ }^{41} 42$ we computed the intra-area correlation of the logarithmic survival times as an indicator of the magnitude of correlation of the outcome within areas.

After estimating an empty multilevel survival model (ie comprising no explanatory variables) for the whole sample (aged 50-79 years), we estimated an empty model in each age group database separately (50-64-year-old and 65-79-year-old individuals). In each age group, separate empty models were also fitted in the three population density strata. We then introduced the characteristics of individuals into the models, and in a final step the socioeconomic contextual variable. The proportionality assumption of the Cox models was tested and found to be valid for each independent variable. For a correct assessment of the magnitude of the individual income effect and socioeconomic contextual effect, we used specific cut-offs in each sample (ie in each age-group database and in each population-density stratum) to divide the variables into four categories.

\section{RESULTS}

Among individuals aged 50-64 years at baseline, 1.2\% (2305/ $192840)$ died from IHD in the 7-year follow-up. Among individuals aged 65-79 years, the corresponding figure was 6.34\% (9403/148 208).

An empty Cox multilevel model fitted to the whole study sample (aged 50-79 years) indicated significant variations in IHD mortality between areas (area-level variance 0.14, p<0.001; IHR 2.36; MHR 1.43; intra-area correlation 0.08; not reported in a table). However, as shown by empty models estimated separately in each age group (50-64 and 65-79 years at baseline), a much larger geographical variability was seen among 50-64-year-old people than among older people, as assessed with the area-level variance, the IHR, the MHR, and the intra-area correlation coefficient (tables 1 and 2). The arealevel variance was more than four times larger in the youngest group; the IHR was 2.91 among people aged 50-64 years, but only 1.71 among those aged $65-79$ years.

Among 50-64-year-old individuals, empty Cox multilevel models stratified by population density indicated that the magnitude of geographical variation increased with population density (table 1). In this age group, significant between-area variations were only found in the highest tertile of population density (the absence of significance in the intermediate population-density stratum may be due to the low number of IHD deaths in the 50-64 years age group). Even if the pattern was less clear among 65-79-year-old individuals, the magnitude of geographical variations in IHD mortality was also the lowest in sparsely populated territories.

Individual variables were then introduced into the models. In both age groups, models that were not stratified by population density indicated a higher IHD mortality among men, older individuals, non-cohabiting persons, individuals with low education and manual workers (table 3). We also found a graded increase in mortality risk with decreasing 20-year cumulated income of individuals. All individual effects tended to be larger among 50-64 than among 65-79-year-old individuals. Inclusion of individual factors led to a $70 \%$ and $57 \%$ decrease in the area-level variance in the two age groups (not reported in a table).

We then took into account the socioeconomic contextual variable. As shown in table 4 , in each age $\times$ population-density stratum, there was a regular increase in the crude rate of IHD mortality with decreasing socioeconomic position of the area of residence. Among 50-64-year-old individuals, differences in IHD mortality by socioeconomic environment were markedly larger in densely than in sparsely populated territories.

We then included the socioeconomic contextual variable into the models for the whole region of Scania (top part of table 5). After adjustment for individual factors, IHD mortality increased regularly with decreasing socioeconomic position of the residential area. The socioeconomic contextual effect was larger among 50-64 than among 65-79-year-old individuals. In both age groups, the area socioeconomic effect was weaker than the individual 20-year cumulated income effect. After including the contextual variable, the between-area variance was equal to $0.04(\mathrm{p}=0.28)$ and $0.02(\mathrm{p}=0.07)$ among 50-64 and 65-79year-old individuals, respectively-that is, $81 \%$ and $62 \%$ lower than in the empty models.

In models stratified by population density (bottom of table 5), we observed, in both age groups, that the socioeconomic contextual effect on IHD mortality tended to increase with population density. We found no area socioeconomic effect in sparsely populated (ie rural) territories, but observed marked socioeconomic contextual effects in the two other tertiles of population density. The socioeconomic contextual effect was particularly strong for the non-elderly residents of densely populated territories (50-64 years at 
Table 3 Individual-level effects* on ischaemic heart disease mortality, Scania, 1996-2002

\begin{tabular}{|c|c|c|}
\hline & \multicolumn{2}{|l|}{ HR $(95 \% \mathrm{Cl})$} \\
\hline & Age $50-64$ years & Age $65-79$ years \\
\hline Male $v$ female & 4.96 (4.45 to 5.54$)$ & 3.31 (2.97 to 3.30$)$ \\
\hline \multicolumn{3}{|l|}{ Age at baseline } \\
\hline First 5-year group & 1.00 & 1.00 \\
\hline Second 5-year group & $2.14(1.90$ to 2.41$)$ & 1.69 (1.60 to 1.79$)$ \\
\hline Third 5-year group & 3.93 (3.51 to 4.41$)$ & 2.88 (2.72 to 3.04$)$ \\
\hline Alone $v$ cohabiting & 2.12 (1.94 to 2.30$)$ & 1.51 (1.45 to 1.58$)$ \\
\hline \multicolumn{3}{|l|}{ 20-year cumulated income } \\
\hline High & 1.00 & 1.00 \\
\hline Mid-high & 1.44 (1.27 to 1.64$)$ & 1.26 (1.19 to 1.34$)$ \\
\hline Mid-low & 2.11 (1.85 to 2.42$)$ & 1.47 (1.37 to 1.58$)$ \\
\hline Low & $2.60(2.25$ to 3.00$)$ & 1.82 (1.69 to 1.97$)$ \\
\hline \multicolumn{3}{|l|}{ Educational attainment } \\
\hline High & 1.00 & 1.00 \\
\hline Medium & 1.09 (0.96 to 1.24$)$ & 1.11 (1.03 to 1.20$)$ \\
\hline Low & $1.23(1.09$ to 1.39$)$ & 1.22 (1.14 to 1.29 ) \\
\hline \multicolumn{3}{|c|}{ Occupation 25 years before } \\
\hline Non-manual & 1.00 & 1.00 \\
\hline Manual & 1.21 (1.08 to 1.35$)$ & $1.14(1.08$ to 1.20$)$ \\
\hline Self-employed & $1.03(0.84$ to 1.27$)$ & 0.99 (0.91 to 1.08$)$ \\
\hline Farmer & 0.59 (0.45 to 0.78$)$ & $0.88(0.81$ to 0.97$)$ \\
\hline
\end{tabular}

baseline). In this specific age and population density subgroup, the area socioeconomic effect was almost as important as the individual income effect.

\section{DISCUSSION}

Our study confirms the existence of an association between socioeconomic environment and IHD mortality, after adjustment for individual socioeconomic factors. It expands on previous literature in showing that the socioeconomic contextual effect on IHD mortality was

- larger among non-elderly adults than among the elderly and

- far stronger in densely than in sparsely populated territories.
As a result, IHD mortality of non-elderly residents of urban territories depended almost as much on the socioeconomic environment as on the 20-year cumulated individual income.

The main strengths of our study include the definition of a large cohort of individuals, the geocoding of participants to highly local areas and the adjustment of models for several socioeconomic indicators over the adult age. However, there were limitations to our study. Firstly, the low number of IHD deaths among individuals aged 50-64 years at baseline (about $99 \%$ of observations were right censored) may have resulted in a weak statistical power to detect between-area variations and socioeconomic contextual effects on IHD. Secondly, and most importantly, we had no information on health-damaging behaviour, healthcare utilisation or social support, preventing us from investigating the mediating mechanisms of the context-IHD association. Even if pioneer studies have started exploring those intermediate processes, ${ }^{16} 172428$ it is a common view that the appropriate way to identify contextual effects is to estimate correlations between contextual factors and health adjusted for classic individual socioeconomic characteristics. We believe that this approach cannot be considered to be explanatory in itself, as a certain part of the associations between contextual characteristics and diseases probably results from the confounding effect of factors that are systematically neglected. For example, a low control on work organisation combined with a high job demand ${ }^{43} 44$ or a high demand combined with a low reward ${ }^{45}$ may increase incidence of IHD; however, no published study has adjusted contextual effects for this factor, which is unevenly distributed among neighbourhoods but not part of the causal pathway between residential context and IHD. ${ }^{16}$ Accordingly, we believe that it is unwise to conclude that truly contextual influences on IHD exist before some of the main mediating processes of the socioeconomic contextual effect are clearly identified.

Geographical variations in IHD were almost completely captured by individual and contextual socioeconomic factors, suggesting that IHD has a strong social dimension. Our study expands on previous literature in showing that the magnitude of geographical variations in IHD mortality and the strength of socioeconomic contextual effects depend on the age of individuals and on the population density of the residential area.

Firstly, we found that socioeconomic contextual effects on IHD mortality were larger among 50-64-year-old individuals than among older individuals. ${ }^{11} 2226$ This may be a consequence

Table 4 Number of deaths from ischaemic heart disease according to the socioeconomic contextual variable, in each stratum of population density, Scania, 1996-2002

\begin{tabular}{|c|c|c|c|c|}
\hline & \multicolumn{2}{|c|}{ Baseline age $50-64$ years } & \multicolumn{2}{|c|}{ Baseline age $65-79$ years } \\
\hline & $\begin{array}{l}\text { Number of } \\
\text { cases/pop }\end{array}$ & Rate (\%) & $\begin{array}{l}\text { Number of } \\
\text { cases/pop }\end{array}$ & Rate $(\%)$ \\
\hline \multicolumn{5}{|l|}{ First tertile of pop density } \\
\hline Low socioeco environment & $195 / 16043$ & 1.2 & $866 / 12368$ & 7.0 \\
\hline Mid-low socioeco environment & $189 / 16042$ & 1.2 & $800 / 12257$ & 6.5 \\
\hline Mid-high socioeco environment & $153 / 15982$ & 1.0 & $722 / 12452$ & 5.8 \\
\hline High socioeco environment & $127 / 16143$ & 0.8 & $635 / 12312$ & 5.2 \\
\hline \multicolumn{5}{|l|}{ Second tertile of pop density } \\
\hline Low socioeco environment & $249 / 16183$ & 1.5 & $957 / 12327$ & 7.8 \\
\hline Mid-low socioeco environment & $164 / 15892$ & 1.0 & $841 / 12406$ & 6.8 \\
\hline Mid-high socioeco environment & $111 / 15998$ & 0.7 & $702 / 12393$ & 5.7 \\
\hline High socioeco environment & $109 / 16158$ & 0.7 & $599 / 12375$ & 4.8 \\
\hline \multicolumn{5}{|l|}{ Third tertile of pop density } \\
\hline Low socioeco environment & $428 / 16106$ & 2.7 & $981 / 12274$ & 8.0 \\
\hline Mid-low socioeco environment & $276 / 16083$ & 1.7 & $895 / 12447$ & 7.2 \\
\hline Mid-high socioeco environment & $186 / 16150$ & 1.2 & $761 / 12257$ & 6.2 \\
\hline High socioeco. environment & $118 / 16040$ & 0.7 & $644 / 12340$ & 5.2 \\
\hline
\end{tabular}


Table 5 Effects of individual cumulated income and socioeconomic environment on ischaemic heart disease mortality in each stratum of population density, from Cox multilevel models adjusted for individual factors, Scania, 1996-2002

\begin{tabular}{|c|c|c|}
\hline & \multicolumn{2}{|l|}{$\mathrm{HR}(95 \% \mathrm{Cl})$} \\
\hline & Age $50-64$ years & Age $65-79$ years \\
\hline \multicolumn{3}{|c|}{ Whole region of Scania } \\
\hline \multicolumn{3}{|c|}{ Cumulated income ( $v$ high) } \\
\hline Mid-high & $1.37(1.21$ to 1.55$)$ & 1.24 (1.17 to 1.32$)$ \\
\hline Mid-low & $1.94(1.70$ to 2.23$)$ & 1.44 (1.34 to 1.54$)$ \\
\hline Low & 2.36 (2.04 to 2.72 ) & 1.78 (1.65 to 1.92$)$ \\
\hline \multicolumn{3}{|c|}{ Socioeconomic environment ( $v$ high) } \\
\hline Mid-high & $1.27(1.10$ to 1.48$)$ & 1.07 (1.00 to 1.14$)$ \\
\hline Mid-low & $1.37(1.18$ to 1.58$)$ & $1.13(1.06$ to 1.21$)$ \\
\hline Low & 1.81 (1.58 to 2.09$)$ & $1.23(1.15$ to 1.31$)$ \\
\hline \multicolumn{3}{|c|}{ First tertile of pop density } \\
\hline \multicolumn{3}{|c|}{ Cumulated income ( $v$ high) } \\
\hline Mid-high & $1.50(1.20$ to 1.89$)$ & 1.20 (1.07 to 1.33$)$ \\
\hline Mid-low & 2.03 (1.59 to 2.59 ) & $1.33(1.18$ to 1.50$)$ \\
\hline Low & $2.12(1.62$ to 2.78$)$ & 1.61 (1.40 to 1.84$)$ \\
\hline \multicolumn{3}{|c|}{ Socioeconomic environment ( $v$ high) } \\
\hline Mid-high & 1.05 (0.82 to 1.35$)$ & 1.00 (0.90 to 1.12$)$ \\
\hline Mid-low & $1.22(0.96$ to 1.56$)$ & $1.07(0.95$ to 1.19$)$ \\
\hline Low & $1.13(0.89$ to 1.44$)$ & 1.11 (0.99 to 1.24$)$ \\
\hline \multirow{2}{*}{\multicolumn{3}{|c|}{ Second tertile of pop density }} \\
\hline & & \\
\hline Mid-high & $1.33(1.05$ to 1.69$)$ & $1.13(1.01$ to 1.26$)$ \\
\hline Mid-low & $1.76(1.36$ to 2.28$)$ & 1.44 (1.27 to 1.62$)$ \\
\hline Low & $2.74(2.07$ to 3.63$)$ & 1.80 (1.56 to 2.07$)$ \\
\hline \multicolumn{3}{|c|}{ Socioeconomic environment ( $v$ high) } \\
\hline Mid-high & $0.92(0.70$ to 1.21$)$ & 1.05 (0.94 to 1.19$)$ \\
\hline Mid-low & $1.19(0.92$ to 1.53$)$ & 1.15 (1.02 to 1.29$)$ \\
\hline Low & $1.48(1.15$ to 1.89$)$ & 1.24 (1.10 to 1.39$)$ \\
\hline \multirow{2}{*}{\multicolumn{3}{|c|}{$\begin{array}{l}\text { Third tertile of pop density } \\
\text { Cumulated income ( } v \text { high) }\end{array}$}} \\
\hline & & \\
\hline Mid-high & $1.38(1.13$ to 1.68$)$ & 1.29 (1.17 to 1.43$)$ \\
\hline Mid-low & $1.94(1.58$ to 2.39$)$ & 1.46 (1.30 to 1.64$)$ \\
\hline Low & $2.30(1.86$ to 2.85$)$ & 1.80 (1.58 to 2.05$)$ \\
\hline \multicolumn{3}{|c|}{ Socioeconomic environment ( $v$ high) } \\
\hline Mid-high & $1.28(1.01$ to 1.62$)$ & 1.12 (1.00 to 1.25$)$ \\
\hline Mid-low & $1.60(1.27$ to 2.00$)$ & 1.23 (1.10 to 1.38$)$ \\
\hline Low & $2.16(1.74$ to 2.70$)$ & $1.35(1.21$ to 1.51$)$ \\
\hline
\end{tabular}

of the development pattern of IHD over the life course, characterised by an accelerated deterioration of the cardiovascular system and a premature onset of the disease for individuals who are cumulating detrimental exposures related to their individual and contextual socioeconomic characteristics. The more frequent and evenly distributed incidence of the disease at older ages, combined with the better health of survivors in deprived areas, ${ }^{22}{ }^{23}$ may explain the weaker socioeconomic contextual effect on IHD mortality observed among elderly people. Therefore, following a perspective presented in a previous work, ${ }^{56}$ it is particularly the public health interventions targeted at premature IHD that need to be contextualised-that is, adapted to the conditions prevailing in each area.

\section{What is already known}

- Previous studies have reported an effect of neighbourhood socioeconomic position on incidence and mortality of ischaemic heart disease (IHD), after adjustment for individual socioeconomic factors.

- Little is known about the strength of socioeconomic contextual effects on IHD mortality in the different age groups and within territories of varying population densities.
Secondly, stronger effects of the socioeconomic environment were found in densely than in sparsely populated territories. It indicates that socioeconomic contextual disparities in IHD mortality only appear within urban territories. Possibly, the clustering of deprived individuals in an area may create detrimental conditions (in terms of resources available and shared values) affecting health-damaging and healthcareseeking behaviour only when a certain degree of concentration of social disadvantage over a given surface is reached. The

\section{What this study adds}

- The analysis of a large Swedish cohort indicated that the magnitude of socioeconomic contextual effects on IHD mortality was much greater among non-elderly than elderly adults, and much larger within urban than within rural territories.

- Among non-elderly residents of urban territories, the socioeconomic contextual effect on IHD mortality was almost as large as the effect of individual 20-year cumulated income.

- Non-elderly residents of deprived urban neighbourhoods therefore constitute a major target for both contextual epidemiology of coronary disease and public health interventions dealing with contextual influences on IHD. 
burden of contextual poverty may be more deeply felt in densely populated territories in which observable signs of material or social deprivation are more visible. ${ }^{47} 48$ Complementarily, environmental hazards such as noise or air pollution may be more common in deprived urban neighbourhoods than in any other place. ${ }^{49-51}$

Combined, the modifying effects of age and population density lead to a particularly marked geographical variability and strong socioeconomic contextual effect on IHD mortality for non-elderly residents of urban territories. In this population group, the socioeconomic contextual effect was almost as high as the effect of individual 20-year cumulated income. It may be particularly within urban territories that the socioeconomic deprivation of the context confronts individuals with life conditions that result in a premature onset of coronary disease. Therefore, non-elderly residents of deprived urban neighbourhoods constitute a major target for both contextual epidemiology of coronary disease and public health interventions aimed at reducing the detrimental effects of the social environment on IHD risk.

Besides the obvious relevance of global policies dealing with the issue of social disparities, the knowledge available on the relationship between the residential environment and IHD may be too scarce to allow the implementation of definite interventions targeting specific contextual influences on IHD. In any case, socioeconomic contextual effects on premature IHD mortality are strong enough within urban territories to deserve high priority research to elucidate their origin.

\section{ACKNOWLEDGEMENTS}

We thank Statistics Sweden, the Center for Epidemiology (National Board of Health and Welfare) and the Region Skåne.

\section{Authors' affiliations}

B Chaix, J Merlo, Community Medicine and Public Health, Department of Clinical Sciences, Malmö University Hospital, Lund University, Malmö, Sweden

B Chaix, Inserm UMR-S 707 (Inserm-Université Pierre et Marie CurieParis6), Paris, France

M Rosvall, Department of Health Sciences, Malmö University Hospital, Lund University, Malmö, Sweden

Funding: This study is part of the LOMAS project ("Socioeconomic disparities in cardiovascular diseases-a longitudinal multilevel analysis"), which is funded by the Swedish Council for Working Life and Social Research (PI Juan Merlo, Dnr 2003-05809) and the Swedish Research Council (PI Juan Merlo, Dnr 2004-6155). BC is also supported by a postdoctoral grant from the French Foundation for Medical Research (SPE20041102299), by the French National Research Agency (HealthEnvironment program number 0015305 ) and by a grant from Région llede-France. MR is also supported by an ALF grant from the Swedish Government (Dnr M:B 39923/2005)

Competing interests: None.

\section{REFERENCES}

1 Yusuf S, Hawken S, Ounpuu S, et al. Effect of potentially modifiable risk factors associated with myocardial infarction in 52 countries (the INTERHEART study): case-control study. Lancet 2004;364:937-52.

2 Murray CJ, Lopez AD. Alternative projections of mortality and disability by cause 1990-2020: Global Burden of Disease Study. Lancet 1997;349:1498-504.

3 Kaplan GA, Keil JE. Socioeconomic factors and cardiovascular disease: a review of the literature. Circulation 1993;88:1973-98.

4 Diez Roux AV. Residential environments and cardiovascular risk. J Urban Health 2003;80:569-89.

5 Merlo J. Multilevel analytical approaches in social epidemiology: measures of health variation compared with traditional measures of association. J Epidemio Community Health 2003:57:550-2.

6 Merlo J, Chaix B, Yang M, et al. A brief conceptual tutorial of multilevel analysis in social epidemiology - linking the statistical concept of clustering to the idea of contextual phenomenon. J Epidemiol Community Health 2005;59:443-9.

7 Chaix B, Merlo J, Subramanian SV, et al. Comparison of a spatial perspective with the multilevel analytic approach in neighborhood studies: the case of mental and behavioral disorders due to psychoactive substance use in Malmö, Sweden, 2001. Am J Epidemiol 2005; 162:171-82.

8 Lawlor DA, Bedford C, Taylor M, et al. Geographical variation in cardiovascular disease, risk factors, and their control in older women: British Women's Heart and Health Study. J Epidemiol Community Health 2003;57:134-40.

9 Lawlor DA, Davey Smith G, Patel R, et al. Life-course socioeconomic position, area deprivation, and coronary heart disease: findings from the British Women's Heart and Health Study. Am J Public Health 2005;95:91-7.

10 Morris RW, Whincup PH, Lampe FC, et al. Geographic variation in incidence of coronary heart disease in Britain: the contribution of established risk factors. Heart $2001 ; 86: 277-83$

11 Martikainen P, Kauppinen TM, Valkonen T. Effects of the characteristics of neighbourhoods and the characteristics of people on cause specific mortality: a register based follow up study of 252,000 men. J Epidemiol Community Health 2003;57:210-17.

12 Sundquist K, Malmstrom M, Johansson SE. Neighbourhood deprivation and incidence of coronary heart disease: a multilevel study of 2.6 million women and men in Sweden. J Epidemiol Community Health 2004:58:71-7.

13 Sundquist K. Correction for Sundquist et al. J Epidemiol Community Health. 58(1): 71-7, J Epidemiol Community Health, 2004;58:259.

14 Armstrong DL, Castorina J. Community occupational structure, basic services, and coronary mortality in Washington state, 1980-1994. Ann Epidemiol 1998:8:370-7.

15 Tonne C, Schwartz J, Mittleman M, et al. Long-term survival after acute myocardial infarction is lower in more deprived neighborhoods. Circulation 2005; 111:3063-70.

16 Diez-Roux AV, Nieto FJ, Muntaner C, et al. Neighborhood environments and coronary heart disease: a multilevel analysis. Am J Epidemiol 1997;146:48-63.

17 Diez Roux AV, Merkin SS, Arnett D, et al. Neighborhood of residence and incidence of coronary heart disease. N Engl J Med 2001;345:99-106.

18 Nordstrom CK, Diez Roux AV, Jackson SA, et al. The association of personal and neighborhood socioeconomic indicators with subclinical cardiovascular disease in an elderly cohort. The Cardiovascular Health Study. Soc Sci Med 2004:59:2139-47.

19 Borrell LN, Diez Roux AV, Rose K, et al. Neighbourhood characteristics and mortality in the Atherosclerosis Risk in Communities Study. Int J Epidemiol 2004;33:398-407.

20 Davey Smith G, Hart C, Watt G, et al. Individual social class, area-based deprivation, cardiovascular disease risk factors, and mortality: the Renfrew and Paisley Study. J Epidemiol Community Health 1998;52:399-405.

21 Sundquist K, Winkleby $M$, Ahlen $\mathrm{H}$, et al. Neighborhood socioeconomic environment and incidence of coronary heart disease: a follow-up study of 25,319 women and men in Sweden. Am J Epidemiol 2004:159:655-62.

22 Waitzman NJ, Smith KR. Phantom of the area: poverty-area residence and mortality in the United States. Am J Public Health 1998;88:973-6.

23 Diez Roux AV, Borrell LN, Haan M, et al. Neighbourhood environments and mortality in an elderly cohort: results from the cardiovascular health study. J Epidemiol Community Health 2004:58:917-23.

24 Brown P, Guy M, Broad J. Individual socio-economic status, community socioeconomic status and stroke in New Zealand: a case control study. Soc Sci Med 2005;61:1174-88.

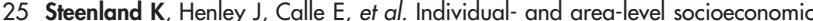
status variables as predictors of mortality in a cohort of 179,383 persons. Am J Epidemiol 2004; 159:1047-56.

26 LeClere FB, Rogers RG, Peters K. Neighborhood social context and racial differences in women's heart disease mortality. J Health Soc Behav 1998:39:91-107.

27 Sundquist K, Theobald $\mathrm{H}$, Yang $M$, et al. Neighborhood violent crime and unemployment increase the risk of coronary heart disease: a multilevel study in an urban setting. Soc Sci Med 2006;62:2061-71.

28 Stiarne MK, Ponce de Leon A, Hallqvist J. Contextual effects of social fragmentation and material deprivation on risk of myocardial infarction-results from the Stockholm Heart Epidemiology Program (SHEEP). Int J Epidemiol 2004;33:732-41.

29 Sundquist J, Johansson SE, Yang M, et al. Low linking social capital as a predictor of coronary heart disease in Sweden: a cohort study of 2.8 million people. Soc Sci Med 2006;62:954-63.

30 Franzini L, Spears W. Contributions of social context to inequalities in years of life lost to heart disease in Texas, USA. Soc Sci Med 2003:57:1847-61.

31 Jones K, Duncan C. Individuals and their ecologies: analysing the geography of chronic illness within a multilevel modelling framework. Health Place $1995 ; 1: 27-40$

32 Leyland AH. Socioeconomic gradients in the prevalence of cardiovascular disease in Scotland: the roles of composition and context. J Epidemiol Community Health 2005;59:799-803.

33 Marinacci C, Spadea T, Biggeri A, et al. The role of individual and contextual socioeconomic circumstances on mortality: analysis of time variations in a city of north west Italy. J Epidemiol Community Health 2004;58:199-207.

34 Merlo J, Gerdtham UG, Lynch J, et al. Social inequalities in health - do they diminish with age? Revisiting the question in Sweden 1999. Int J Equity Health 2003;2:2

35 Merlo J, Chaix B, Ohlsson $\mathrm{H}$, et al. A brief conceptual tutorial of multileve analysis in social epidemiology-using measures of clustering in multilevel logistic regression to investigate contextual phenomena. J Epidemiol Community Health 2006;60:290-7.

36 Chaix B, Rosvall M, Lynch J, et al. Disentangling contextual effects on causespecific mortality in a longitudinal 23-year follow up study: impact of population density or socioeconomic environment? Int J Epidemiol 2006;35:633-43. 
37 Andersen P, Gill R. Cox's regression model for counting processes, a large sample study. Ann Stat 1982; 10:1100-20.

38 Therneau T. Survival R package, version 2.20. http://www.r-project.org/ (accessed 4 Nov 2006).

39 Therneau T, Grambsch P, Pankratz V. Penalized survival models and frailty. J Comput Graph Stat 2003;12:156-75.

40 Larsen K, Merlo J. Appropriate assessment of neighborhood effects on individual health: integrating random and fixed effects in multilevel logistic regression. Am J Epidemiol 2005;161:81-8.

41 Lam KF, Ip D. REML and ML estimation for clustered grouped survival data. Stat Med 2003;22:2025-34.

42 Wong MC, Lam KF, Lo EC. Multilevel modelling of clustered grouped survival data using Cox regression model: an application to ART dental restorations. Stat Med 2006;25:447-57.

43 Karasek R, Baker D, Marxer F, et al. Job decision latitude, job demands, and cardiovascular disease: a prospective study of Swedish men. Am J Public Health 1981;71:694-705.

44 Haan MN. Job strain and ischaemic heart disease: an epidemiologic study of metal workers. Ann Clin Res 1988;20:143-5.
45 Lynch J, Krause N, Kaplan GA et al. Workplace demands, economic reward, and progression of carotid atherosclerosis. Circulation 1997;96:302-7.

46 Merlo J, Chaix B, Yang M, et al. A brief conceptual tutorial of multilevel analysis in social epidemiology-interpreting neighbourhood differences and the effects of neighbourhood characteristics on individual health. J Epidemiol Community Health 2005;59:1022-9.

47 Wandersman A, Nation M. Urban neighborhoods and mental health. Psychological contributions to understanding toxicity, resilience, and interventions. Am Psychol 1998:53:647-56.

48 Geis KJ, Ross CE. A new look at urban alienation: the effect of neighborhood disorder on perceived powerlessness. Soc Psychol Q 1998;61:232-46.

49 Chaix B, Gustafsson S, Jerrett $M$, et al. Children's exposure to nitrogen dioxide in Sweden: investigating environmental injustice in an egalitarian country. $J$ Epidemiol Community Health 2006:60:234-41.

50 Finkelstein MM, Jerrett M, Deluca $P$, et al. Relation between income, air pollution and mortality: a cohort study. Can Med Assoc J 2003;169:397-402.

51 van Kempen EE, Kruize H, Boshuizen HC, et al. The association between noise exposure and blood pressure and ischemic heart disease: a meta-analysis. Environ Health Perspect 2002;110:307-17. 